\title{
環境負荷評価としてのエクセルギー解析*1
}

\begin{tabular}{|c|c|}
\hline 良彦1,*2 & 赤司 豊 $1, * 3$ \\
\hline 白 鳥 紀 -1 & 中 島 謙 -2 \\
\hline
\end{tabular}

1法政大学工学部

2 筑波大学大学院工学研究科構造工学専攻

3独立行政法人 物質材料研究機構

J. Japan Inst. Metals, Vol. 66, No. 9 (2002), pp. 885-888

(C) 2002 The Japan Institute of Metals

\section{Exergy Analysis for the Integrated Evaluation of Environmental Impacts}

Yoshihiko Soeno ${ }^{1, * 2}$, Yutaka Akashi1,*3, Hiromitsu Ino ${ }^{1}$, Kiiti Siratori ${ }^{1}$, Kenichi Nakajima ${ }^{2}$ and Kohmei Halada ${ }^{3}$

${ }^{1}$ College of Engineering, Hosei, University, Koganei 184-8584

${ }^{2}$ College of Engineering, University of Tsukuba, Tsukuba 305-8577

${ }^{3}$ National Institute for Materials science, Tsukuba 305-0047

\begin{abstract}
It is important to assess environmental impacts of materials or products properly. But the typical method called Life Cycle Assessment has many problems. Above all, it is crucial that various kinds of environmental impacts cannot be integrated. We present an attempt to use the exergy concept to express environmental impacts. Exergy has been used to analyze thermal efficiency of the production process. However, to apply exergy to environmental problems, exergy of materials is important since chemi$\mathrm{cal}$ reaction of the wastes cause environmental problems. Exergy expresses gap of free energy between a given state and that of environment. Thus, the concept of exergy gives potential of environmental impacts. We analyzed impacts of life cycle of both steel and aluminum cans as an example. We have proposed a new diagram that represents exergy and mass flow in a system. The diagram consists of triangles and arrows. The three sides of triangle represent inputs, products and wastes of a unit process. The length and width of arrow express the magnitudes of exergy and mass, respectively. It was estimated that the total exergy of material wastes from life cycle of one thousand cans made of aluminum and steel are $540 \mathrm{MJ}$ and $305 \mathrm{MJ}$, respectively. If the recycling rate is 100 per cent, the amounts of exergy are reduced to $49 \mathrm{MJ}$ and $10 \mathrm{MJ}$. It is concluded that the present analysis based on exergy is useful to evaluate potential environmental impacts caused by mass discarding of materials. But it is still insufficient to evaluate impacts of trace toxic chemicals such as dioxin.
\end{abstract}

(Received April 25, 2002; Accepted June 13, 2002)

Keywords: exergy, environmental impacts, life cycle assessment (LCA), aluminum can, steel can, mass balance, wastes

\section{1. は じめに}

適正な材料や製品の環境負荷評価は, 環境問題を改善する ためには不可欠である。現在，その代表例として，LCA (Life Cycle Assessment) という手法があるが，様々な問題 を抱えている。その中でも，環境影響 (Impact)を統合する 手法がないことが問題であると考えられる. 本研究では, 工 クセルギーを環境負荷ポテンシャルとみて, LCA に組み込 むことを試みる。

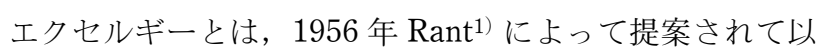
来, 主に熱の有効利用の尺度として用いられてきた。 また, それは, ある状態と環境との自由エネルギーの差であること から「働きかけ」の能力を意味する. したがって, 廃棄物質

\footnotetext{
*1 2002 年 3 月 29 日日本金属学会春期大会において発表

*2 法政大学大学院生 (Graduate Student Hosei University)

*3 法政大学大学生 (Undergraduate Student Hosei University)
}

がエクセルギーをもっていれば，それだけ環境に対して働き かけるので, エクセルギーの廃棄を環境負荷ポテンシャルと してみることもできる ${ }^{2)}$. また, 環境問題を考える上で, 廃 棄物質によって引き起こされる問題が重要であるので, 本研 究は, 化学エクセルギーなどを持つ物質の廃棄に注目する.

今回, アルミ缶抢よびスチール缶のライフサイクルを例と して，システムの環境負荷の大きさおよびリサイクルの効果 をエクセルギーによって表現し, 環境負荷評価としてのエク セルギー解析の有用性を示す.

\section{2. 解 析 対 象}

今回, 解析の対象としたのは以下の二つである.

(1) アルミ二ウム午 $350 \mathrm{ml} \mathrm{LD}$ 缶(アルミ胴 $12.2 \mathrm{~g}$, アル ミ蓋 $4 \mathrm{~g}$ )

(2) スチール缶 $350 \mathrm{ml} \mathrm{LD}$ 缶 (スチール胴 $28 \mathrm{~g}$, アルミ蓋 $4 \mathrm{~g})$ 
解析の対象とするシステムは，「資源採取」から「製造」， 「使用」,「消費」，「リサイクル」，「廃棄」および「輸送」を 含めた全体とする. 本研究では, 飲料容器本体のライフサイ クルを中心としているため, 内容物, 資本設備, 輸送時に消 費される相包材・パレット等は対象外とした.

\section{3. 解 析 方 法}

あるシステムのエクセルギー解析を行うには，システム内 の各プロセスに打ける熱掞よび物質の入力・出力を把握しな ければならない。アルミニウムやスチールといった主系列の 物質は著者らによって行われた「飲料缶のライフサイクルア セスメント $\rfloor^{3)} に よ り$ 算出されている(元データの出所はその 引用文献を参照)。しかし，このインベントリーデータは， 物質收支およびエネルギー収支の厳密な考慮がなされていな い.そこで，システム全体における各プロセス内の主要な化 学反応の知識を用いて，それぞれの収支を考慮し，データを 補った，具体例として，アルミニウムの精錬プロセスに抢け る物質収支を Table 1 に示す。

また，システム内のプロセス全ての物質収支を考慮するこ とは，LCAのインベントリーデータの問題点を発見するた めの手段としても有効である ${ }^{2)}$. 例えば，石灰石を焼成し， 生石灰にするプロセス(アルミナ製造プロセスの前段階)の実 測データがなかったので，文献 1)では，投入のエネルギー や環境負荷をゼロとして計算を行っている，本研究では，そ のプロセスが $「 \mathrm{CaCO}_{3}$ (石灰石 $)=\mathrm{CaO}($ 生石灰 $)+\mathrm{CO}_{2}($ 二酸 化炭素)」の反応に基づくことから，理論的に必要な最小限 のエネルギーおよび物質の投入および算出を計算し，解析を 行った.

各プロセスの物質収支が適切に考慮されているのであれ ば，入出力の関係は，各要素をそれぞれの物質量とする入力 ベクトル $I$ と出力ベクトル $O$ を用いて,

$$
O=P I
$$

と表現することができる．ここで，Pはプロセスを表す行列 である，また，各物質の単位当りのエクセルギーを表すべク

Table 1 Mass balances in Hall-Heroult process. The data are obtained from inventory data of $\mathrm{LCA}^{3)}$ and supplemented with calculations $\left(^{*}\right)$ based on the equations of the chemical reactions in the process.

INPUT (Resources)

\begin{tabular}{lc}
\hline Alumina $/ \mathrm{kg}$ & 1.8889 \\
\hline Synthetic cryolite $/ \mathrm{kg}$ & 0.0300 \\
\hline Aluninum flouride $/ \mathrm{kg}$ & 0.0180 \\
\hline Carbon anodes $/ \mathrm{kg}$ & 0.4300 \\
\hline water $/ \mathrm{kg}$ & 0.0096 \\
\hline & \\
\hline fuel $/ \mathrm{kg}$ & 0.1771 \\
\hline $\mathrm{O}_{2}{ }^{*} / \mathrm{kg}$ & 0.5290 \\
\hline $\mathrm{N}_{2}{ }^{*} / \mathrm{kg}$ & 0.0005 \\
\hline Total $/ \mathrm{kg}$ & 3.0831 \\
\hline Electricity $/ \mathrm{MJ}$ & 57.535 \\
\hline
\end{tabular}

OUTPUT(Products and wastes)

\begin{tabular}{ll}
\hline $\mathrm{Al} / \mathrm{kg}$ & 1.0000 \\
\hline Alumina*/kg & 0.0182 \\
\hline $\mathrm{HF} * / \mathrm{kg}$ & 0.0214 \\
\hline $\mathrm{CO}_{2}{ }^{*} / \mathrm{kg}$ & 1.2222 \\
\hline $\mathrm{NaF}^{*} / \mathrm{kg}$ & 0.0180 \\
\hline $\mathrm{Waste} \mathrm{solids} / \mathrm{kg}$ & 0.0967 \\
\hline $\mathrm{CO}_{2} / \mathrm{kg}$ & 0.5910 \\
\hline $\mathrm{NO}_{2} / \mathrm{kg}$ & 0.0015 \\
\hline $\mathrm{SO}_{2} / \mathrm{kg}$ & 0.0084 \\
\hline $\mathrm{Water} / \mathrm{kg}$ & 0.1057 \\
\hline Total$/ \mathrm{kg}$ & 3.0831 \\
\hline
\end{tabular}

トル $e_{\mathrm{u}}$ をそれ゙れ対応する物質に掛け合わせれば，エクセ ルギーロス $\Delta e$ を

$$
\Delta e=e_{\mathrm{u}}(O-I)
$$

と表現することができる(ここで, 電力は入力ベクトル $I$ の 一つの要素に加えてあり，そのエクセルギーへの変換係数は 1 である.). 各物質の単位当りのエクセルギーは, JIS ${ }^{4)}$ 等 によって示されており，それらのデータを用いて解析を行っ た。

解析結果の例として, アルミ精錬プロセスを Fig. 1 に示 す. Fig. 1 は，エクセルギ一解析の結果を表現するために, 我々が提案する新しい表記方法である。それは，三角形によ って一つのプロセスを表し, 矢印によって質量(物質)拉よび エクセルギーの流れを表す。三角形の 3 辺がそれぞれ資源 投入サイド，生産サイド，廃棄サイドを表し，矢印の幅が質 量, 長さがエクセルギーを表す。この表記方法を用いれば, エクセルギーと質量という基本情報を 1 つの図に表示する ことができ，三角形の大きさによってプロセスの大きさ(物 質の流入 ·流出量) を図示できる. 排熱抢よび不可逆損失 は，投入のエクセルギーから製品(副生物も含む) と物質廃棄 のエクセルギーを差し引くことによって一括して算出した. 両者を分けて求めることは, プロセスのエクセルギー効率改 善という観点から重要である5)が，ここでは行っておらず， 排熱は式 (2)のエクセルギーロスに含まれる格好となって いる.

\section{4. 解析結果および考察}

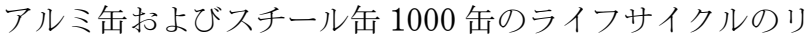
サイクル率や焼却の有無を変化させ，システム全体における エクセルギー解析を行った結果を Table 2 に示す. Table 3 は，アルミ缶のライフサイクルの各段階(製造·加工·廃

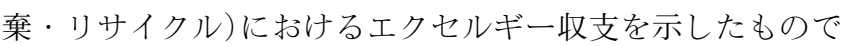
ある。

Fig. 2 にリサイクル率 0\%の場合およびリサイクル率 100\%の場合の解析結果 (アルミ缶の場合)を示す．後述する が，それらの図はリサイクルの効果をより適正に表現してお り，また，プロセス内の各段階におけるエクセルギーと物質

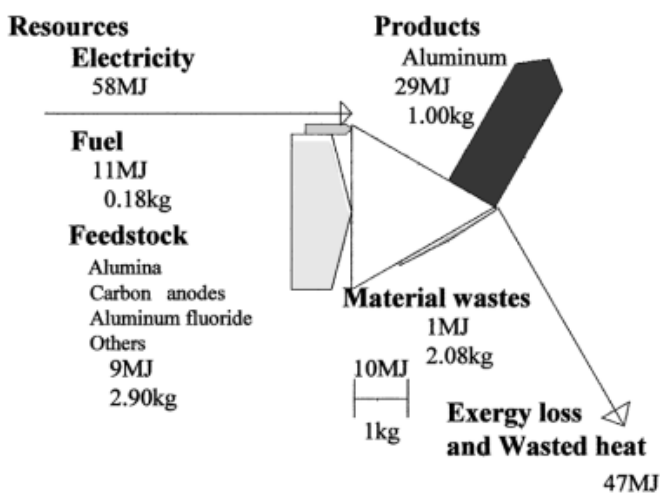

Fig. 1 Exergy analysis of a Hall-Heroult process. Three sides of triangle represent resources, products, and wastes of the process. The length and width of an arrow express the magnitudes of exergy and mass, respectively. 
Table 2 Calculated exergy per 1000 cans.

(a) Aluminum cans INPUT

\begin{tabular}{|c|c|c|c|c|}
\hline & Electricity & Fuel & Feedstock & Total \\
\hline & $E / \mathrm{MJ}$ & $E / \mathrm{MJ}$ & $E / \mathrm{MJ}$ & $E / \mathrm{MJ}$ \\
\hline Recycling: $0 \%$ & 2105 & 1455 & 321 & 3881 \\
\hline Recycling: $100 \%$ & 1016 & 876 & 137 & 2029 \\
\hline Recycling: $75 \%$ & 1289 & 1021 & 183 & 2493 \\
\hline $\begin{array}{l}\text { Recycling: } 75 \% \\
\text { Incineration: } 15 \%\end{array}$ & 1354 & 1020 & 182 & 2556 \\
\hline
\end{tabular}

OUTPUT

\begin{tabular}{|c|c|c|c|c|}
\hline & Byproducts & $\begin{array}{l}\text { Material } \\
\text { wastes }\end{array}$ & $\begin{array}{l}\text { Wasted heat } \\
\text { and exergy } \\
\text { loss }\end{array}$ & Total \\
\hline & $E / \mathrm{MJ}$ & $E / \mathrm{MJ}$ & $E / \mathrm{MJ}$ & $E / \mathrm{MJ}$ \\
\hline Recycling: $0 \%$ & 373 & 540 & 2968 & 3881 \\
\hline Recycling: $100 \%$ & 343 & 49 & 1637 & 2029 \\
\hline Recycling: $75 \%$ & 351 & 172 & 1970 & 2493 \\
\hline $\begin{array}{l}\text { Recycling: } 75 \% \\
\text { Incineration: } 15 \%\end{array}$ & 420 & 92 & 2045 & 2557 \\
\hline
\end{tabular}

(b) Steel cans

INPUT

(MJ)

\begin{tabular}{lccccccr}
\hline & Electricity & & Fuel & & Feedstock & & Total \\
\cline { 2 - 3 } & $E / \mathrm{MJ}$ & & $E / \mathrm{MJ}$ & & $E / \mathrm{MJ}$ & & $E / \mathrm{MJ}$ \\
\hline Recycling: $0 \%$ & 305 & & 371 & & 561 & 1237 \\
\hline Recycling: $100 \%$ & 178 & & 213 & & 40 & 431 \\
\hline
\end{tabular}

OUTPUT

\begin{tabular}{|c|c|c|c|c|}
\hline & Byproducts & $\begin{array}{l}\text { Material } \\
\text { wastes }\end{array}$ & $\begin{array}{l}\text { Wasted heat } \\
\text { and exergy } \\
\text { loss }\end{array}$ & Total \\
\hline & $E / \mathrm{MJ}$ & $E / \mathrm{MJ}$ & $E / \mathrm{MJ}$ & $E / \mathrm{MJ}$ \\
\hline Recycling: $0 \%$ & 387 & 304 & 545 & 1236 \\
\hline Recycling: 100\% & 47 & 10 & 374 & 431 \\
\hline
\end{tabular}

という基本情報の入力 · 出力の様子を一目で把握することが できる. なお, リサイクル率 $100 \%$ の場合においても, アル ミニウム一次地金の製造量がゼロとならないのは, 加工プロ セスに㧍いてアルミスクラップが発生するためであり，その スクラップは有効に使われるものと仮定し, 副生物として取 り扱って解析を行った.

リサイクルの効果を厳密に表現するためには, 比較対象で あるリサイクルプロセスを導入しない場合の環境負荷, 特に 「廃棄」段階における環境負荷の見積もりが十分でなければ ならない, つまり, 文献 1)に打ける「廃棄」段階の環境負 荷とは, 運搬, 埋め立てという安易な廃棄プロセスにおける $\mathrm{CO}_{2}, \mathrm{NO}_{x}, \mathrm{SO}_{x}$ の排出であり, それらの排出量の見積もりも 不十分であり, 廃棄プロセスの環境負荷として十分なもので はない, 一方, 本研究において, 環境負荷とは物質のエクセ ルギー, つまり環境負荷ポテンシャルの廃棄であり, 廃棄の 環境負荷評価に新しい視点を提供するとともに，リサイクル の効果をより明確に示すものとなっている.

Fig. 3 に廃棄されたエクセルギーと質量によって表現され たアルミ缶のリサイクルおよび焼却の効果を示す。縦軸にラ
Table 3 Exergy balances in each phase in life cycle of 1000 aluminum cans. Mass of 1000 Aluminum cans is $16.2 \mathrm{~kg}$.

\begin{tabular}{|c|c|c|c|}
\hline \multicolumn{4}{|c|}{ Material production of 27 kilogram of aluminum } \\
\hline INPUT & $E / \mathrm{MJ}$ & OUTPUT & $E / \mathrm{M}$ \\
\hline Electricity & 1853 & Aluminun & 791 \\
\hline Fuel & 1123 & Red mud & 0 \\
\hline Alumina & 0 & Material wastes & 62 \\
\hline Carbon anodes & 303 & Others & 50 \\
\hline Aluninum flouride & 0 & \multirow{2}{*}{ Exegry loss and wasted heat } & \multirow{2}{*}{2391} \\
\hline Others & 15 & & \\
\hline Total & 3294 & Total & 3294 \\
\hline
\end{tabular}

\begin{tabular}{|c|c|c|c|}
\hline \multicolumn{4}{|c|}{ Manufacturing of 16.2 kilogram of aluminum cans } \\
\hline INPUT & $E / \mathrm{MJ}$ & OUTPUT & $E / \mathrm{MJ}$ \\
\hline Alminum & 791 & Aluminum can & 469 \\
\hline Electricity & 252 & Aluminun scrap & 322 \\
\hline Fuel & 331 & Material wastes & 9 \\
\hline Others & 2 & \multirow{2}{*}{ Exegry loss and wasted heat } & \multirow{2}{*}{576} \\
\hline Ttal & 585 & & \\
\hline \multicolumn{3}{|r|}{ Total } & 1376 \\
\hline
\end{tabular}

\begin{tabular}{|c|c|c|c|}
\hline \multicolumn{4}{|c|}{ Discarding of 16.2 kilogram of aluminum cans } \\
\hline INPUT & $E / \mathrm{MJ}$ & OUTPUT & $E / \mathrm{MJ}$ \\
\hline Electricity & 0 & Aluminun & 469 \\
\hline Fuel & 1 & Material wastes & 0 \\
\hline Aluminum can & 469 & \multirow{2}{*}{ Exegry loss and wasted heat } & \multirow{2}{*}{1} \\
\hline Others & 0 & & \\
\hline Total & 470 & Total & 470 \\
\hline \multicolumn{4}{|c|}{ Recycling of 16.2 kilogram of aluminum cans } \\
\hline INPUT & $E / \mathrm{MJ}$ & OUTPUT & $E / \mathrm{MJ}$ \\
\hline Aluminum can & 469 & Aluminun & 469 \\
\hline Electricity & 9 & Material wastes & 3 \\
\hline Fuel & 88 & \multirow{2}{*}{ Exegry loss and wasted heat } & \multirow{2}{*}{95.4} \\
\hline Others & 1 & & \\
\hline Total & 567 & Total & 567 \\
\hline
\end{tabular}

イフサイクルにおける合計の廃棄物質のエクセルギーをと り，横軸にその質量をとる．屯た，円の大きさがライフサイ クルに投入されたエクセルギーの大きさを表し, 円グラフの 中の割合がその内訳を表す．Fig. 3 より，リサイクルの増加 とともに, 廃棄物質のエクセルギーは減少することが分か る. 更に, Fig. 3 の矢印によって示されるように, リサイク ル率 75\%のプロセスに使用済み缶 15\%の焼却プロセスを加 えたことにより，80 MJ の廃棄物質(アルミ缶)のエクセル ギーの低減が生じる．ここで, 焼却プロセスとは, アルミ缶 のアルミを酸化させ，エクセルギーをゼロにし，そのときに 生じる熱(アルミニウムとアルミナの自由エネルギーの差分) を回収するプロセスである.

本研究には次のような問題点がある. 1 つは電力という 2 次エネルギーを 1 次エネルギーまで遡って解析していない 点である.つまり, 電力の生産に伴うプロセスのエクセル 

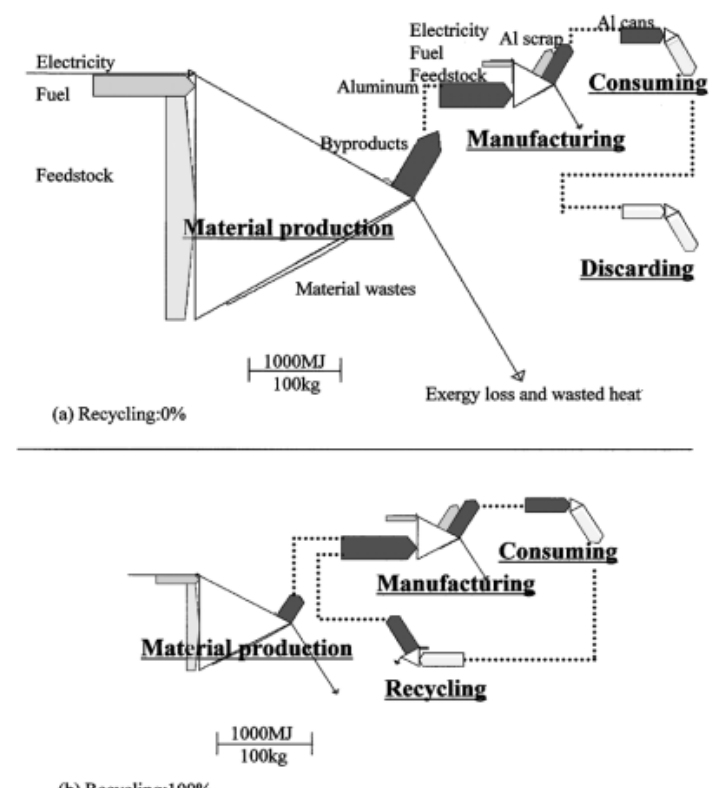

Fig. 2 Integrated exergy and mass flows in the processes of life cycle of one thousand aluminum cans in cases of (a) recycling: $0 \%$ and (b) recycling: $100 \%$

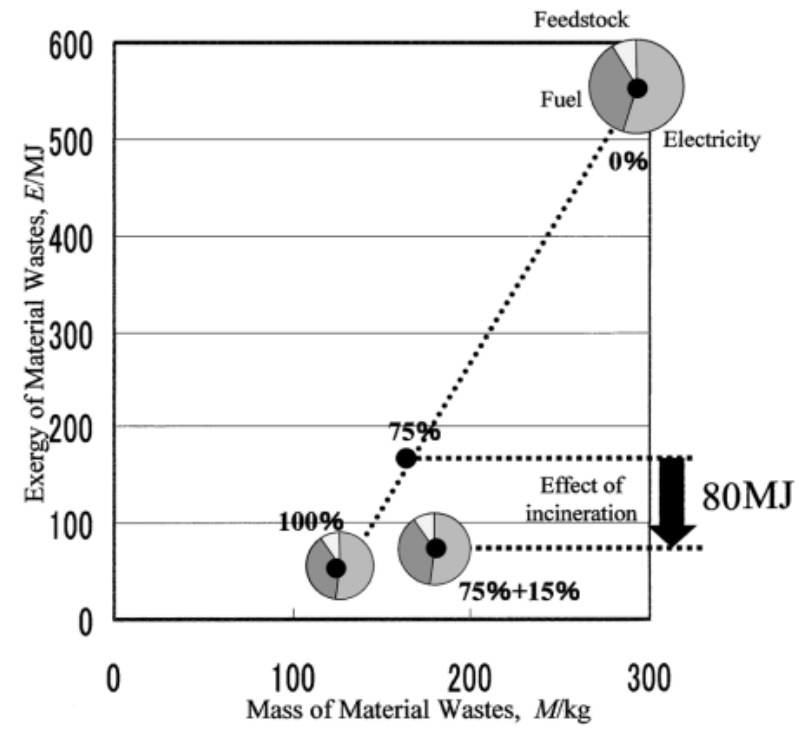

Fig. 3 Effect of recycling and incineration presented by wastes in the processes of life cycle of one thousand aluminum cans. Size of circle is the amount of input exergy. The numbers in this figure mean the percentage of recycling and that of additional incineration.

ギ一廃棄を除外している. 現状に打いて，火力・水力・原子 力発電に伴う廃棄のエクセルギーを計算するに至らなかっ た.これは今後の課題である.
2 つは，エクセルギーと毒性の関係である．エクセルギー がゼロであれば毒性はゼロであるので，エクセルギーを統合 的な環境影響の 1 つの指標とみることは有用であると考え られるが，エクセルギーの大きさと毒性との間に比例的な関 係があるわけではないので, 毒性の絶対的尺度としてみるこ とは困難である。例えば，ダイオキシンのような微量物質が 挙げられる. エクセルギ一解析は，このような微量で強い環 境影響を及ぼす物質の解析には十分ではなく, 本研究が対象 としたような多量の物質の廃棄が問題となるような場合に有 効性を発揮すると考えられる. 微量物質の扱い方も今後の課 題である.

\section{5. ま め}

本研究は, エクセルギーを環境負荷ポテンシャルとみてア ルミ缶およびスチール缶の環境負荷評価を行い, Table 2 や Fig. 2 に示すように新しい視点でリサイクルの効果を明らか にし, 多量物質の廃棄が問題となるような場合のエクセル ギ一解析の有用性を示した．この結果は LCAのそれとは異 なる. 本研究によって行われたエクセルギ一解析おいて, リ サイクルの効果とは, 物質のエクセルギー廃棄, つまり環境 負荷ポテンシャルの低減であり，「廃棄」段階の環境負荷の 見積もりが不十分な LCA に比べ，より適正なリサイクルの 評価を提供するものと考えられる。 今後, LCA を行う場合 は全てエクセルギ一解析も併せて行うべきである, と提案す る.

また，本研究では，エクセルギー解析を行うための新しい 表記方法を提案した。それは, Fig. 1, Fig. 2 に示したよう に，三角形によってプロセスを表し，矢印の長さと幅によっ てエクセルギーと質量という基本情報を表すもので，視覚的 にシステムの流れを一目で把握できる.

今後の課題として，様々な応用事例を積み重ねるととも に, 電力の生産活動に伴う廃棄物質 (放射性廃棄物質など) や，ダイオキシンのような非常に毒性の高い微量物質のエク セルギーの評価方法の確立が挙げられる.

文献

1) Z. Rant: Exergie, Ein neues Wort für technische Arbeits-fahigkeit, Forsch. Ing.-Wes 22 (1956) 36-37.

2) Robert U. Ayres and Leslie W. Ayres: Accounting for Resources, 2, (Edward Elgar Pub., 1999) pp. 1-61.

3) K. Nakajima, H. Ino and K. Halada: J. Japan Inst. Metals 64(2000) 591-596 (in Japanese).

4) Japanese Industrial standards Committee: JIS Z 9204 (1991) pp. 1-33.

5) T. Akiyama: Kinzoku 71(2001) 10-13. (in Japanese) 